Original Research Article

\title{
Assessment of knowledge, attitude and self-care activities among type-2 diabetic patients attending a tertiary care teaching hospital
}

\author{
Ashutosh Ashok Kakade ${ }^{1}$, Ipseeta Ray Mohanty ${ }^{1}$, Sandeep Rai ${ }^{2}$
}

\begin{abstract}
${ }^{1}$ Department of Pharmacology, MGM Medical College, Kamothe, Navi Mumbai, Maharashtra, India

${ }^{2}$ Department of Medicine and Division of Diabetology, MGM Medical College, Navi Mumbai, Maharashtra, India
\end{abstract}

Received: 16 August 2016

Accepted: 27 September 2016

*Correspondence to:

Dr. Ipseeta Ray Mohanty,

Email:

ipseetamohanty@yahoo.co.in

Copyright: (C) the author(s), publisher and licensee Medip Academy. This is an openaccess article distributed under the terms of the Creative Commons Attribution NonCommercial License, which permits unrestricted noncommercial use, distribution, and reproduction in any medium, provided the original work is properly cited.

\begin{abstract}
Background: Poor awareness, negative attitudes and inadequate self-care practices among diabetic patients are some of the important variables influencing the progression of diabetes and its complications, which are largely preventable through education and involvement of the patient.

Methods: A hospital based cross sectional study was conducted among type 2 diabetics attending diabetes clinic in tertiary care hospital. Knowledge and attitude towards making lifestyle changes were evaluated using a semi structured questionnaire. To assess the diabetes self-care activities associated with glycemic control the Diabetes Self-care Management Questionnaire consisting of four subscales 'Glucose management', 'Dietary control', 'Physical activity' and 'Health Care Use' was used.

Results: A total of 61 diabetic patients consented and participated in the study of whom $56.66 \%$ were male and $43.33 \%$ female. Majority of the respondents $(33.30 \%)$ were in the age group more than 60 years, $43.3 \%$ belonged to upper middle class, $21.3 \%$ were obese and majority had duration of disease between 5 to 10 years. Only $30 \%$ of the total diabetic patients had achieved good glycemic control. There was a significant difference between knowledge ( $p$ $<0.05$ ) but not attitude towards self-care activities between the glycemic controlled versus the uncontrolled diabetic patients. Among self-care practices, following a controlled diet $(\mathrm{p}<0.05)$ and observing strict glucose management ( $\mathrm{p}<0.05)$ were significantly associated with achieving glycemic control.

Conclusions: As evidenced by the study, patients who were regularly involved in self-care practices (especially dietary control and glucose management) achieved better glycemic control. Therefore, interventions to increase diabetic patient self-care behaviour are needed to reduce poor glycemic control.
\end{abstract}

Keywords: Attitude, Diabetes, Glycemic control, Knowledge, Self-care

\section{INTRODUCTION}

Diabetes is fast gaining the status of a potential epidemic in India with more than 62 million diabetic individuals currently diagnosed with the disease. ${ }^{1}$ Diabetes mellitus is associated with microvascular and macrovascular complications and presents a high mortality and morbidity, with significant reduction in the quality of life of patients. Evidence from large randomized controlled trials has established the benefits of improved glycemic control in reducing microvascular and macrovascular complications associated with diabetes. ${ }^{2}$ Although a number of internal and external factors affect glycemic control, it is widely accepted that good self-care practices translates into improved glycemic control. ${ }^{1,4,5,6}$

It is therefore essential to provide comprehensive services including health education regarding the self care management of the disease in order to prevent the debilitating complications associated with diabetes. Self care in the form of adherence to diet and drugs, blood glucose monitoring, foot care, exercise; recognition of symptoms is crucial elements in secondary prevention. Helping patients to achieve their best possible level of 
glycemic control will require the utilization of appropriate therapy, appropriate monitoring, and comprehensive instruction for diabetes self-management.

In addition, many studies have shown that poor disease awareness and negative attitudes towards self-care practices among diabetic patients are some of the important variables influencing the progression of diabetes and its complications, which are largely preventable through education and involvement of the patient. Therefore, the present study focused on obtaining baseline information regarding the various aspects of self-care that can influence the glycemic control in patients such as basic diabetes information, having the right attitude, complying with recommended diabetic diet, exercise routine, monitoring glucose levels and health care .Such an assessment of patient's knowledge, attitude and practices about diabetes and its care is imperative in developing various intervention strategies and educational material.

The study was designed to evaluate the participant' knowledge regarding the disease and self-care activities, attitude towards making lifestyle changes to help control diabetes using questionnaire developed by Mazenet al. ${ }^{4}$ In addition, the Diabetes Self-Management Questionnaire (DSMQ) was used to assess self-care activities which can predict glycaemic control. The DSMQ is a 16 item questionnaire designed to assess four subscales, 'Glucose Management' (GM), 'Dietary Control' (DC), 'Physical Activity' (PA), and 'Health-Care Use' (HU), as well as a 'Sum Scale'. The knowledge, attitude and self care activities score of the diabetic patients with and without glycemic control were compared to obtain meaningful information. In addition the correlation of the glycemic control with knowledge attitude and diabetes self care practice were determined

\section{METHODS}

Necessary approval from the Institutional Ethics Committee was obtained before initiating the study. The present study is a prospective, observational, crosssectional, descriptive study conducted in the departments of Medicine and Pharmacology, MGM Medical College, Kamothe, Navi Mumbai. Type II diabetes mellitus patients attending the medicine OPD for consultation, who conformed to the specified inclusion and exclusion Criteria were enrolled for the study.

\section{Inclusion criteria}

- Aged $\geq 18$ years of age who were diagnosed with Type II DM ${ }^{7}$

- Patients who agree to sign the consent form.

\section{Exclusion criteria}

- $\quad$ Patients with Type 1 diabetes mellitus
- Pregnant women, including those with gestational diabetes.

- Patients who could not complete the questionnaire.

- Hospitalized and/or with psychiatric disorder during the data collection time (since there is self-care assessment and questionnaire investigation).

\section{Study procedure}

Patients fulfilling the inclusion and exclusion criteria were included in the study after explaining the aim of the study. Written informed consent was obtained from each patient. The socio-demographic profile and disease information were filled up on a performa specifically designed for the study. In addition, the questionnaire developed by Mazenet al and diabetes self-management Questionnaire (DSMQ) was administered to assess participants' knowledge, attitude and current actions relating to diabetes self-care activities associated with glycemic control. ${ }^{4}$ The Diabetes Self-care Management Questionnaire consisting of four subscales 'Glucose management', 'Dietary control', 'Physical activity' and 'Health Care Use' was administered to the patients. ${ }^{4-5}$ The data was collected, tabulated and analyzed. The patients were categorized as those who achive glycemic control and those without glycemic control. The statistically significant differences between knowledge, attitude, Diabetes Self-care Management between the groups were determined.

\section{Statistical analysis}

The analyses were performed using SPSS 21.0.0 (SPSS Inc., Chicago, IL, USA). In all analyses a P-value of $<0.05$ (two-tailed test) was considered as criterion of statistical significance.

\section{RESULTS}

\section{Baseline characteristics}

Baseline characteristics of the respondents are depicted in Table 1. A total of 61 diabetic patients consented and participated in the study of whom $56.66 \%$ were male and $43.33 \%$ female. Age ranged from 34 years to 66 years in the sample with maximum of the respondents $(33.33 \%)$ of the age more than 60 years. Socio-economic status was assessed by categorizing the patient into lower, lower middle, upper middle and upper class according to Kuppuswamy classification. Most of the respondents $(43.3 \%)$ belonged to upper middle class. $21.3 \%$ of the participants were obese and majority had duration of disease between 5 to 10 years. Only $30 \%$ of the total diabetic patients had achieved good glycemic control.

\section{Knowledge and attitude}

The mean total score of $14 \pm 3.3$ was obtained (in the questionnaire pertaining to knowledge regarding self-care activities) among diabetics with good glycemic control as 
compared to $12.03 \pm 3.6$, among those diabetics with poor glycemic control.As shown in Table 2 there was a significant difference between knowledge $(p<0.05)$ but not attitude towards self-care activities between the glycemic controlled versus the uncontrolled diabetic patients.

Table 1: Baseline characteristics of type II diabetic patients.

\begin{tabular}{|c|c|c|c|c|}
\hline S. No & Baseline characteristics & $\begin{array}{l}\text { Glycemic control } \\
\text { achieved group }(\mathrm{N}=18)\end{array}$ & $\begin{array}{l}\text { Glycemic control not } \\
\text { achieved group }(\mathrm{N}=\mathbf{4 2})\end{array}$ & $\begin{array}{l}\text { Total Number } \\
\text { (Percentage) }\end{array}$ \\
\hline \multirow[t]{5}{*}{1} & Age & & & \\
\hline & $<40$ years & 27.77 & 07.14 & 13.33 \\
\hline & $41-50$ years & 33.33 & 28.57 & 30 \\
\hline & $51-60$ years & 22.22 & 23.80 & 23.33 \\
\hline & $>60$ years & 16.66 & 40.47 & 33.33 \\
\hline \multirow[t]{3}{*}{2} & Gender & & & \\
\hline & Male & 55.55 & 57.14 & 56.66 \\
\hline & Female & 44.44 & 42.85 & 43.33 \\
\hline \multirow[t]{5}{*}{3} & Socioeconomic status & & & \\
\hline & Upper class & 22.22 & 09.52 & 13.33 \\
\hline & Upper Middle & 22.22 & 52.38 & 43.33 \\
\hline & Lower Middle & 33.33 & 28.57 & 30 \\
\hline & Lower & 22.22 & 02.38 & 8.33 \\
\hline \multirow[t]{4}{*}{4} & BMI & & & \\
\hline & Normal $<25 \mathrm{~kg} / \mathrm{m}^{2}$ & 33.33 & 30.9 & 31.6 \\
\hline & Over Weight: $\left(25-29.5 \mathrm{~kg} / \mathrm{m}^{2}\right)$ & 44.44 & 47.6 & 46.6 \\
\hline & Obese: $>30 \mathrm{~kg} / \mathrm{m}^{2}$ & 22.22 & 21.4 & 21.66 \\
\hline \multirow[t]{4}{*}{5.} & Duration of Disease & & & \\
\hline & $<5$ years & 50 & 64.2 & 60 \\
\hline & 5-10 years & 33.33 & 21.4 & 25 \\
\hline & $>10$ years & 16.66 & 14.2 & 15 \\
\hline \multirow[t]{3}{*}{5.} & Antidiabetic therapy & & & \\
\hline & OHA alone & 94.44 & 88.09 & 90 \\
\hline & Insulin + OHA & 05.55 & 11.90 & 10 \\
\hline \multirow[t]{6}{*}{6.} & Co-Morbidities & & & \\
\hline & Hypertension & 38.88 & 33.33 & 35 \\
\hline & Thyroid & & & 0 \\
\hline & Nephropathy & 05.55 & & 6.66 \\
\hline & Glaucoma & & 2.3 & 1.6 \\
\hline & Hyperpigmentation & & 2.3 & 1.6 \\
\hline
\end{tabular}

OHA: Oral hypoglycemic agents, BMI: Basal mass index (weight $/ \mathrm{height}^{2}$ ) in $\mathrm{kg} / \mathrm{m}^{2}$

Table 2: Knowledge, attitude and Diabetes self-care activities scores among diabetic patients with and without glycemic control.

\begin{tabular}{|llll|}
\hline Variables & $\begin{array}{l}\text { Glycemic } \\
\text { control } \\
\text { achieved } \\
(\mathbf{N}=\mathbf{1 8})\end{array}$ & $\begin{array}{l}\text { Glycemic } \\
\text { control not } \\
\text { achieved } \\
(\mathbf{N}=\mathbf{4 2})\end{array}$ & P value \\
\hline Knowledge & $14 \pm 3.3$ & $12.03 \pm 3.6$ & 0.024 \\
\hline Attitude & $7.2 \pm 2.46$ & $7.97 \pm 2.4$ & NS \\
\hline $\begin{array}{l}\text { Diabetes } \\
\text { Self-care }\end{array}$ & $1.85 \pm 0.7$ & $1.62 \pm 0.9$ & NS \\
Sum Scale & & & \\
\hline
\end{tabular}

\section{Diabetes self-care practices}

Mean Glucose management score in the glycemic control achieved group was found to be $9.59 \pm 1.41$ as compared to $8.60 \pm 2.4$ score obtained in the glycemic control not achieved group. Similarly the 'dietary control' mean score in the glycemic control achieved group was found to be $8.49 \pm 1.46$ compared to $7.61 \pm 1.1$ in the glycemic control not achieved group The mean score for physical activity and health care use were found to be $4.78 \pm 1.2$ and $5.14 \pm 0.97$ respectively in the good glycemic control group as compared to $4.80 \pm 1.17$ and $4.97 \pm 2.1$ respectively among glycemic control not achieved 
patients. Finally, the sum scale score was found to be $1.85 \pm 0.7$ in the glycemic control achieved group as compared to $1.62 \pm 0.9$ obtained in the glycemic control not achieved group (Figure 1).

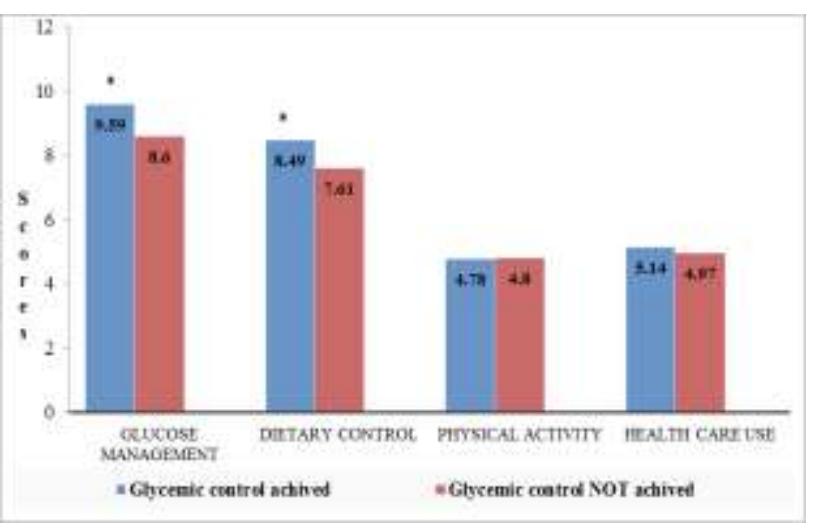

Figure 1: Diabetes Self-care practice scores among diabetic patients with and without glycemic control. $* \mathbf{P}<0.05$ Vs Glycemic control not achieved group.

\section{DISCUSSION}

The present study is a hospital based cross sectional study conducted in the diabetes clinic of tertiary care hospital focusing on evaluation of knowledge, attitude, self care practices among diabetes patients and its relation with glycemic control. In the present study majority of the respondents $(33.33 \%)$ belonged to the age group of more than 60 years. Elderly group are vulnerable population generally suffering from multiple ailments and may have compromised self-care activities. This observation is supported by the similar studies conducted by Karampadmaat et al and Shah at encountered majority of the patients in the age group of 55 years.

Study findings were majority of the patients with poor glycemic control belonged to this age group. In the present study it was observed that the proportion of male patients were more $(56.66 \%)$ then female patients. Similar studies conducted by Karampadmaat et al and Shah at encountered majority of the patients in the age group of 55 years.

Majority of the patients belonged to the middle socioeconomic class and literacy level found in the present study was $90 \%$. These results do not concur with the findings reported by Shah et al. who found $60 \%$ of patients from low socio-economic status and $36 \%$ of these patients were illiterates. ${ }^{8,9}$ No association between glycemic control among the diabetic patients and socioeconomic class was observed in the present study. In the present study, $21.66 \%$ patients were obese while studies from literature have reported less number of obese diabetic patients. Majority of diabetic patients enrolled for the study had duration of disease less than 5 years. This concurs with previous reports. ${ }^{5}$ Hypertension was most common comorbidity encountered in the present study.

Glycemic control was evaluated based on fasting blood sugar levels. Patients with fasting blood sugar levels <than $110 \mathrm{mg} / \mathrm{dl}$ based on Consensus Statement on Guidelines for Glycemic Control provided by American College of Endocrinology were classified as those who had achieved glycemic control and those who did not, based on their fasting blood sugar levels more than 110 $\mathrm{mg} / \mathrm{dl} .{ }^{10}$ Knowledge, attitude and self-care practices were compared across the two groups and significant associations were evaluated. Few numbers of the respondents $18(30 \%)$ achieved glycemic control in the present study unlike various studies in literature which reported $75(64 \%)$ of the diabetic patients with optimum glycemic control. ${ }^{8}$ Nonetheless, the limitation of the present study is the small sample size.

The highlight of the study is that it will help in identifying the barriers against glycemic control. One of the barriers that have been identified in the study is poor self-care activities practiced by the diabetic patients. Therefore, diabetes self-management education (DSME) should be a critical element of care for all people with diabetes. Diabetes self-management education should be an on-going process of facilitating the knowledge, skill, and ability necessary for diabetes self-care. In order to implement DSME interventions it is imperative that the baseline self-care practices and needs of the individual with diabetes are determined based on which the program can be designed with this point of view the study was designed.

Knowledge is an outcome to the degree that it is actionable (i.e., knowledge that can be translated into self-management behaviour). Poor awareness, negative attitudes and self-care practices among diabetic patients are some of the important variables influencing the progression of diabetes and its complications, which are largely preventable. In the present study a significant difference in the knowledge level regarding diabetes and its self-care was observed between the two groups of patients (with and without glycemic control). It may be speculated that eventually the right knowledge regarding the disease process and its control will translate into responsible behaviour for diabetes control. No significant difference in the attitude towards self-care was observed between the groups. This results do not concur with the findings of study by Coonrod at el who found that while knowledge levels related to diabetes, diet, and exercise improved, the changes were not statistically significant. ${ }^{3,4}$ Similarly, participants expressed increased motivation towards weight loss, healthful eating, exercise and positive lifestyle choices. However, these changes were not statistically significant as assessed by the attitude scores.

American Diabetic Association has defined selfmanagement education as the process of providing the 
person with diabetes the knowledge and skill that is needed to perform self care, manage crises and make life style changes. The American Association of Diabetes Educators Outcome Standards for Diabetes Education specifies self-care management behaviour as the key outcome. Effective self-management is one (but not the only) contributor to longer term, higher-order outcomes such as clinical status (e.g., control of glycemia, blood pressure, and cholesterol), health status (e.g., avoidance of complications), and subjective quality of life. Thus, patient self-management behaviours are at the core of the outcomes evaluation. In the present study a validated tool: Diabetes Self-Management Questionnaire (DSMQ) was used to assess self-care activities. The DSMQ is a 16 item questionnaire designed to assess four subscales, 'Glucose Management' (GM), 'Dietary Control' (DC), 'Physical Activity' (PA), and 'Health-Care Use' (HU), as well as a 'Sum Scale'.

As evidenced by the study results, among self-care practices, a significant difference $(\mathrm{p}<0.05)$ in dietary choices and glucose management practices $(\mathrm{p}<0.05)$ were observed between the patients with good and poor glycemic control. However no difference between the physical activity and health care scores was seen between the two groups. There was a significant difference between the patient following a healthy diet, and glucose management with their glycemic control. The finding was consistent with studies in literature with this parameters. ${ }^{4}$

The strengths of this investigation are identifying not only the various aspects of self-care behaviour practiced by diabetic patients but also their knowledge and attitudes that could influence the behaviours. Diabetes self-care includes a range of activities (e.g., self-monitoring of blood glucose, eating a low-saturated-fat diet, and checking one's feet). Because self-care is multidimensional, it is necessary to assess each component separately rather than to combine scores across components. Therefore various aspects of Diabetic Self Care: 'Glucose Management', 'Dietary Control', 'Physical Activity', and 'Health-Care Use' were assessed in the present study using standard questionnaire. The results of the present study have provided comprehensive baseline information on diabetes self-care activities practiced by patients, based on which future interventions will be planned. Such information can also be shared among patients so that they can be motivated for selfcorrective behaviour that would have favourable effect on their glycemic control.

\section{CONCLUSION}

As evidenced by the study, patients who were regularly involved in self-care practices (especially dietary control and glucose management) achieved superior glycemic control. Therefore, an initiative for diabetes selfmanagement education among patients is a critical element for good glycemic control. Regular inculcation of health education, making the patient aware regarding the disease and encouraging self-care management during treatment will reduce health care burden and help achieve optimal glycemic control.

\section{Funding: No funding sources \\ Conflict of interest: None declared \\ Ethical approval: The study was approved by the Institutional Ethics Committee}

\section{REFERENCES}

1. Sutharson L, Hariharan RS, Vamsadhara C. Drug Utilization Study in Diabetology outpatient of a tertiary Hospital, Indian Journal Pharmacology. 2003;35:23740.

2. Al-Akour NA, Khader YS, Alaoui AM. Glycemic Control and Its Determinants among Patients with type 2 Diabetes Mellitus Attending a Teaching Hospital. J Diabetes Metab. 2011;2:129.

3. Coonrod BA, Betschart J, Harris MI. Frequency and Determinants of Diabetes Patient Education among Adults in the US Population. Diabetes Care. 1994; 17:852-8.

4. Elkurd M, Nakata J, Voelkel B, Wadud M, Joy H. Lewis. Effect of Educational Intervention on Type II Diabetes Mellitus Control Open Journal of Preventive Medicine. 2014;4:454-8.

5. Schmitt. The Diabetes Self-Management Questionnaire (DSMQ): development and evaluation of an instrument to assess diabetes self-care activities associated with glycaemiccontrol. Health and Quality of Life Outcomes. 2013;11:138.

6. Kumar N, Gupta N, Kishore J. Kuppusamy's socioeconomic scale: Updating income ranges for year. Indian J Public Health. 2012:56:103-4.

7. IDF Type 2 Diabetes Management Guidelines NDEI. Ndei.org. 2016 [cited 1 August 2016]. Available from: http://www.ndei.org/international-diabetes-federationguidelines.aspx.html

8. Karam P, Bele SD, Bodhare TN, Valsangkar S. Evaluation of knowledge and self care Practices in diabetic patients and their role In disease management, national journal of community medicine. 2012;3(1).

9. Shah VN, Kamdar PK, Shah N. Assessing the knowledge, attitudes and practice of type 2 diabetes among patients of Saurashtra region, Gujarat. Int J Diabetes Dev Ctries. 2009;29:118-22.

10. IDF Type 2 Diabetes Management Guidelines. NDEI. Ndei.org. 2016 [cited 1 August 2016]. Available from: http://www.ndei.org/international-diabetes-federationguidelines.aspx.html.

Cite this article as: Kakade AA, Mohanty IR, Rai S. Assessment of knowledge, attitude and self-care activities among type- 2 diabetic patients attending a tertiary care teaching hospital. Int $\mathrm{J}$ Basic Clin Pharmacol 2016;5:2458-62. 